\title{
Cell Therapy Decreases Inflammation and Improves the Morphology of the Lung Parenchyma in a Murine Model of Cigarette Smoke-Induced Emphysema
}

\author{
Nathália Longhini-dos-Santos, Valter Abraão Barbosa-de-Oliveira, Talita Stessuk, Marna Eliana \\ Sakalem, João Tadeu Ribeiro-Paes
}

\begin{abstract}
Chronic Obstructive Pulmonary Disease (COPD) is characterized by a limitation of gas exchange, associated with an enhanced pulmonary inflammatory response to noxious particles and gases. The pulmonary emphysema, within the spectrum of COPD, is characterized by destruction of alveolar walls with consequent progressive dyspnea. To the present day, there is no effective clinical treatment for COPD, and the available therapeutic approaches are only palliative. In this context, the aim of this study was to verify the effectiveness of cell therapy with a pool of bone marrow mononuclear cells (BMMC) and bone marrow mesenchymal stromal cells (BMMSC) in an experimental model of cigarette smoke-induced emphysema in mice. To induce pulmonary emphysema, female mice $(n=60)$ of the strain $\mathrm{C57BL} / 6$ (treated animals) were exposed to cigarette smoke, 3 times a day for 90 consecutive and uninterrupted days. Another group of animals (control, $\mathbf{n = 1 5}$ ) was exposed only to ambient air. Treated and control animals were comparatively evaluated regarding the therapeutic transplantation effects of the pool of BMMC or BMMSC from male C57BL/6-EGFP (Enhanced Green Fluorescent Protein) donors. The results showed that cell therapy with either BMMC or BMMSC determined morphological recovery of the pulmonary parenchyma and the reduction of inflammation. No improvement in functional parameters was observed. In conclusion, cell therapy with a pool of BMMC or BMMSC promotes the morphological recovery of the lung parenchyma and reduces inflammation in the lungs of smoke-induced pulmonary emphysema in mice.
\end{abstract}

Index Terms - Bone marrow mesenchymal stromal cells, Bone marrow mononuclear cells, Cell therapy, COPD, Pulmonary emphysema.

Nathália Longhini-dos-Santos, Institute of Biomedical Sciences, University of São Paulo, São Paulo, Brazil

Valter Abraão Barbosa-de-Oliveira, Institute of Biomedical Sciences, University of São Paulo, São Paulo, Brazil

Talita Stessuk, Institute of Biomedical Sciences, University of São Paulo, São Paulo, Brazil

Marna Eliana Sakalem, Department of Biotechnology, São Paulo State University, UNESP, Assis, Brazil

João Tadeu Ribeiro-Paes, Department of Biotechnology, São Paulo State University, UNESP, Assis, Brazil

The study was financially supported by Fundação para o Desenvolvimento da UNESP (Fundunesp), Assis City Hall (SP, Brazil), CIVAP/Saúde (SP, Brazil) and scholarships were granted by Coordination for the Improvement of Higher Education Personnel (CAPES - Brazil).

\section{INTRODUCTION}

Chronic Obstructive Pulmonary Disease (COPD) is a serious and worldwide public health problem, with high prevalence and considerable economic and social burden [1]. The World Health Organization (WHO) estimates that 210 million individuals currently suffer from the disease, with 80 millions of these in moderate or severe stages [2]. Currently, COPD is considered the fifth leading cause of death and, by 2020 , it may reach the third position, due to the continuous exposure of the world population to risk factors, especially cigarette smoking, which accounts for $85 \%$ of the cases of COPD [1], [2].

Within the COPD spectrum, pulmonary emphysema is characterized by the destruction of alveolar walls and distension of air spaces distal to the terminal bronchiole, with the initial presence of an inflammatory infiltrate without apparent fibrosis [1]. Cigarette smoking is the principal risk factor for emphysema [1], [2]. Other causal factors include air pollution and occupational exposure to pollutants, which contribute to accelerate the morphological destruction and functional impairment of the lung parenchyma, leading to a gradual loss of gas exchange capacity and progressive dyspnea [1].

In the past few years, cell therapy has been studied for the treatment of a variety of different pathologies, and some therapeutic approaches in animal models and in human patients with positive outcome have been described in the literature [3]- [6]. The effective migration of exogenous stem cells to the lung has been detected in humans [7] and animal models [8], in different experimental conditions. The attraction and migration of cells to the lung, as well as the recovery of the pulmonary parenchyma in COPD animal models after bone marrow-derived cell transplantation [9], [10] support the application of cell-based therapy in lung diseases.

The mononuclear bone marrow fraction (bone marrow mononuclear cells - BMMC), composed of undifferentiated cells, hematopoietic and mesenchymal stem cells (BMMSC), and differentiated cells (lymphocytes, neutrophils and others), has an important role in normal tissue homeostasis, as well as in wound healing or pathological conditions [16], [17]. In this context, the characteristics of both BMMC and 
BMMSC support the use of either cell population in the treatment of lung diseases. One of the most used approaches to investigate possible therapies and treatments to human diseases consists on the use of animal models [10], and this is also the case for investigations of COPD. In the specific context of pulmonary disease investigation, exposure of laboratory animals to cigarette smoke has gained prominence in recent years, since it mimics the pathophysiological characteristics of the disease in humans [4], [11]- [15]. Considering the aim of the present study, which was to test the efficacy of a pool of stem cells, consisting of BMMC or BMMSC, an animal murine model was used, and emphysema was induced with cigarette-smoke.

\section{MATERIALS AND METHODS}

\section{A. Animals}

Male and female C57BL/6 mice (approx. 8 weeks of age) were used in this study. BMMC and BMMSC were harvested from male EGFP mice (C57BL/6-Tg (CAG-EGFP) C14-Y01-FM131Osb), and transplanted into female mice not carrying the EGFP gene. A total of 75 female animals were divided into the following treatment groups (15 animals/group): UN - untreated animals, with no exposure to cigarette smoke, nor treatment with cells or $\alpha$-MEM culture medium; Sm - animals exposed to cigarette smoke, but not to cells or to culture medium; Sm/Med - animals exposed to cigarette smoke that received an infusion of culture medium; Sm/BMMC - animals exposed to cigarette smoke that received an infusion of BMMC; and Sm/BMMSC - animals exposed to cigarette smoke that received infusion of BMMSC. This study followed the standards established in the 251/97 ordinances of the Brazilian National Health Council (Conselho Nacional de Saúde, Brazil), and was approved by the Ethics Committee on Animal Use (CEUA; project number 021/2011) of the Faculty of Sciences and Letters of the São Paulo State University (UNESP, SP, Brazil Campus of Assis).

\section{B. Emphysema Induction}

For pulmonary emphysema induction, mice were placed in an inhalation chamber designed as described in Kozma et al. (2014), and which consisted of a cigarette smoking device (for the uptake and distribution of cigarette smoke) linked to an animal containment system. Female mice were exposed to cigarette smoke three times daily ( 1 hour of exposure in three periods: $8 \mathrm{am}, 12 \mathrm{pm}$ and $4 \mathrm{pm}$ ), for 7 days per week, for 90 consecutive days. Each hour of exposure was divided into three 20-min cycles where mice were exposed to the smoke of commercial filter cigarettes (Derby Vibrante, red package, Souza Cruz SA, Rio de Janeiro, Brazil) for $15 \mathrm{~min}$, followed by $5 \mathrm{~min}$ in ambient air. Each cigarette contained $0.8 \mathrm{mg}$ of nicotine, $10 \mathrm{mg}$ of tar and $10 \mathrm{mg}$ of carbon monoxide. The mean concentration of carbon monoxide within the chamber ranged from 350-400 ppm during the 15-min smoke exposure periods.

\section{Bone Marrow Mononuclear Cells (BMMC) Harvesting}

$\mathrm{BMMC}$ were isolated from male EGFP mice $(\mathrm{n}=5)$ using the protocol described in Longhini-dos-Santos et al. (2013) [10].

\section{Bone Marrow Mesenchymal Stromal Cells (BMMSC) Harvesting and Growth Analysis}

Bone marrow mesenchymnal stromal cells (BMMSC) were harvested from the femurs of male EGFP mice $(n=5)$, sacrificed by cervical dislocation. Femural epiphyses were sectioned and bone marrow cells were removed by flushing with $\alpha$-MEM medium (Gibco, New York, USA) using a syringe. Cell suspensions were homogenized and centrifuged at $380 \mathrm{~g}$ for 10 minutes. The supernatant was discarded and the pellet was resuspended in $\alpha$-MEM medium supplemented with $20 \%$ fetal bovine serum (FBS; HyClone, Utah, USA) with $2 \%$ antibiotic-antimycotic mixture (Gibco, New York, USA) and incubated at $37^{\circ} \mathrm{C}$ with $5 \% \mathrm{CO}_{2}$. On the 15 th day of culture, viable cells were diluted in $\alpha$-MEM medium for a final density of $5 \times 10^{5}$ cells $/ \mathrm{mL}$, and then transplanted into mice (see below).

\section{E. Immunophenotyping}

For immunophenotyping, isolated BMMC and BMMSC were fixed in $2 \%$ paraformaldehyde, labeled with fluorochrome-conjugated antibodies (see below) and analyzed by flow cytometry using a FACSCalibur (Becton Dickinson, USA). Flow cytometry data were analyzed using WinMDI 2.8. BMMC were labeled with anti-Flk2-PE, anti-Sca-1-Cy7-PE and anti-c-Kit-APC antibodies, and BMMSC were labeled with antibodies recognizing negative selection markers (anti-CD45, anti-Ter-119, anti-CD11 and anti-cKit, conjugated to APC), as well as positive selection markers anti-CD90-PE, anti-CD73-PE and anti-Sca-1-Cy7-PE antibodies.

\section{F. Cell Transplantation}

Cell transplantation was performed 16 days after the end of the period of exposure to cigarette smoke, by intravenous infusion of cells through the tail vein. Sm/BMMC and $\mathrm{Sm} / \mathrm{BMMSC}$ groups received $0.4-\mathrm{mL}$ infusions of a pool of BMMC $\left(7 \times 10^{6}\right.$ cells $\left./ \mathrm{mL}\right)$ or BMMSC $\left(5 \times 10^{5}\right.$ cells $\left./ \mathrm{mL}\right)$, respectively. The $\mathrm{Sm} / \mathrm{Med}$ group was infused with $0.4 \mathrm{~mL}$ of vehicle ( $\alpha$-MEM medium) only. Mice were analyzed 21 days after cell transplantation.

\section{G. Lung Function Analysis}

For lung function analysis, animals were anesthetized by an intraperitoneal injection of $250 \mathrm{mg} / \mathrm{kg}$ of Thiopentax (Cristália Chemicals Pharmaceuticals Ltda., São Paulo, Brazil), 21 days after cell transplantation, tracheotomized (with a 20-G catheter) and connected to a ventilator for small animals (FlexiVent, Scireq, Canada), which was set to a tidal volume of $10 \mathrm{~mL} / \mathrm{kg}$, an RR of 120 breaths $/ \mathrm{min}$, and a positive end-expiratory pressure of $3 \mathrm{~cm}$ of $\mathrm{H}_{2} \mathrm{O}$. Muscle paralysis was induced by intraperitoneal injection of $1 \mathrm{mg} / \mathrm{kg}$ pancuronium bromide. The following lung function parameters were measured: airway resistance (Raw), damping/resistance of lung tissue (Gtis), and lung tissue elastance (Htis).

\section{H. Histological Analysis}

After lung function analysis, animals were euthanized and 
the lungs were removed. The tracheae were cannulated, attached to a perfusion apparatus, and lungs were perfused with paraformaldehyde $4 \%$ for $24 \mathrm{~h}$, and kept inflated with sustained positive pressure $\left(20 \mathrm{~cm}\right.$ of $\left.\mathrm{H}_{2} \mathrm{O}\right)$ throughout the fixation period. Embedded lung tissue samples were cut into 5 - $\mu \mathrm{m}$ sections, stained with hematoxylin/eosin (HE), and the presence/extent of emphysema was assessed by measuring the mean linear intercept ( $\mathrm{Lm}$, in $\mu \mathrm{m}$ ) in light microscopy images, as described by Weibel, in 1963 [18].

\section{Immunohistochemistry}

The immunohistochemical analysis was performed essentially as described in Suratt et al (2003). Lung histological samples were labelled with an anti-metalloproteinase 9 (MMP-9) antibody (Santa Cruz Biotechnology, Inc., Santa Cruz, CA, USA). Then, sections were washed and incubated with biotinylated goat Anti-B7014 secondary antibodies (Sigma-Aldrich). Finally, sections were washed, counter-stained with hematoxylin and observed in a Zeiss Axio Scope A1 microscope (Carl Zeiss Microscopy GmbH, Germany).

\section{J. Fluorescence Microscopy}

For the detection of EGFP-positive cells, organ samples were embedded in Tissue Tek OCT® (Optimal Critical Temperature Compound, Sakura Finetek, Torrance, USA). Endogenous peroxidase activity was blocked by incubating $3-\mu \mathrm{m}$ sections four times with 30 volumes of hydrogen peroxide (5 min/incubation). After blocking, sections were washed 3 times with PBS (3 $\mathrm{min} / \mathrm{wash}$ ), and stained with DAPI (1:300) for 30 minutes, at room temperature. After staining, sections were washed 3 times in PBS, mounted with coverslips and stored at $-20{ }^{\circ} \mathrm{C}$ in the dark. Samples were analyzed on a Zeiss LSM 780 - Observer Z1/ZEN confocal microscope (Carl Zeiss Microscopy GmbH, Germany).

\section{K. Statistical Analysis}

The values from the lung function analysis and Lm measurements were analyzed by Kruskal-Wallis ANOVA and post-hoc Dunn's test. focal microscope (Carl Zeiss Microscopy GmbH, Germany).

\section{RESULTS}

\section{A. MSC Were Isolated Efficiently from Mouse Bone Marrow}

After BMMC and BMMSC purification from mouse bone marrow, surface markers found in the different cell populations (by flow cytometry) were investigated, in order to evaluate the efficiency of separation of BMMC and BMMSC (Fig. 1). In the pool of BMMC, $0.08 \%$ of cells were positive for the BMMC markers Sca-1 and c-kit and negative for Lin and FLK-2 (Fig. 1A). In BMMSC populations, $33.91 \%$ of cells were positive for Sca-1, CD90 and CD73 and negative for CD45, Ter119, CD11 and c-kit (Fig. 1B). These results indicate that the $\mathrm{BMMSC}$ isolation protocol was adequate, effectively eliminating hematopoietic progenitors.

\section{B. Treatment with BMMC or BMMSC reverts alveolar morphology in mice with emphysema}

To allow transplanted cells to be easily traced in treated animals, bone marrow cells from male EGFP mice were transplanted into treated female mice not expressing EGFP.
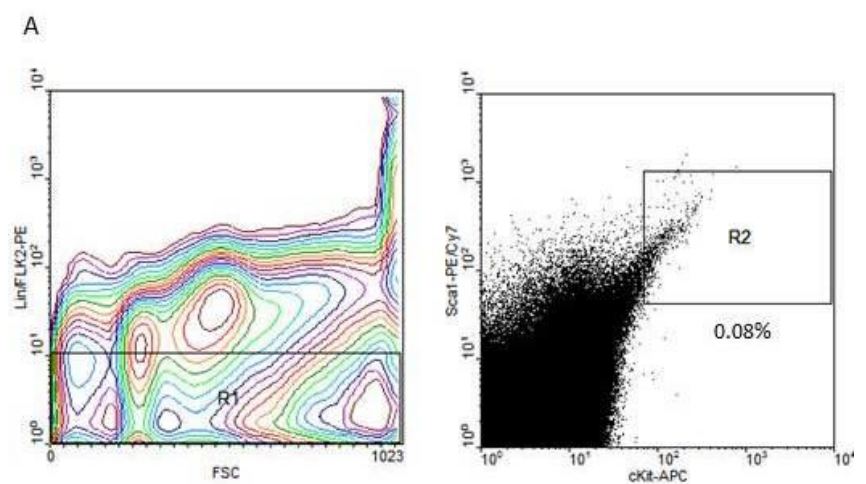

B
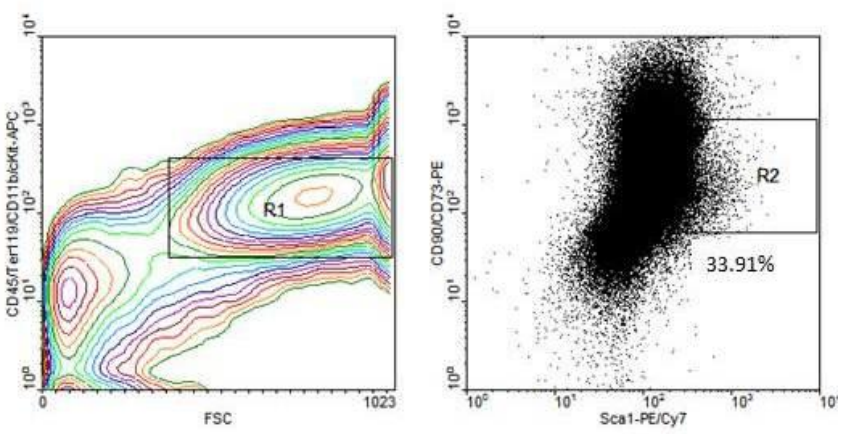

Fig. 1. Flow cytometry analysis of bone marrow mononuclear cells (BMMC; in A) or bone marrow mesenchymal stromal cells (BMMSC; in B) isolated from male EGFP mice (C57BL/6J background), and labeled with fluorochrome-conjugated antibodies against BMMC (A) or BMMSC (B) surface markers. In each panel, gate R2 represents double-positive populations obtained from gate $\mathrm{R} 1$ (exclusion markers).

After cell transplantation, a clear migration of EGFP-positive BMMC and BMMSC to the lungs of treated mice was observed by fluorescence microscopy (Fig. 2). Overall, these data confirm that transplanted BMMC and BMMSC had migrated to the target organ 21 days after cell transplantation.

Pulmonary emphysema is characterized by the increase in the air spaces, which can be observed in histological images of lung tissue as an increase in the 'mean linear intercept'
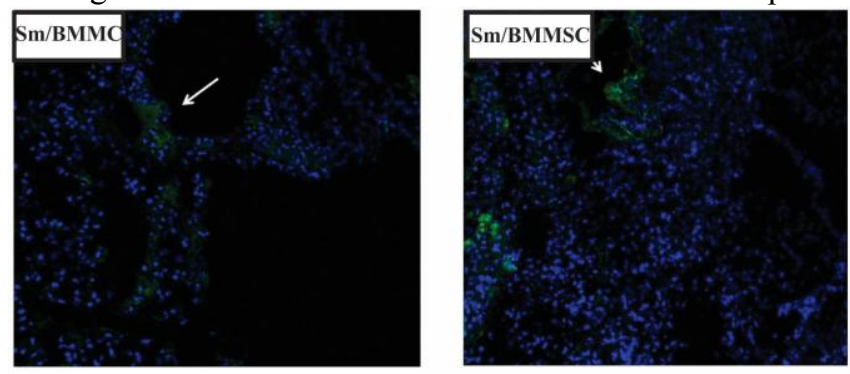

Fig. 2. Histological sections of lung tissue from female mice transplanted with bone marrow mononuclear cells (BMMC) or bone marrow mesenchymal stromal cells (BMMSC) from male EGFP mice from the same background 
strain $(\mathrm{C} 57 \mathrm{BL} / 6 \mathrm{~J})$. Lungs were removed and processed for histological examination 21 days after cell transplantation. Sections were analyzed by fluorescence microscopy for the

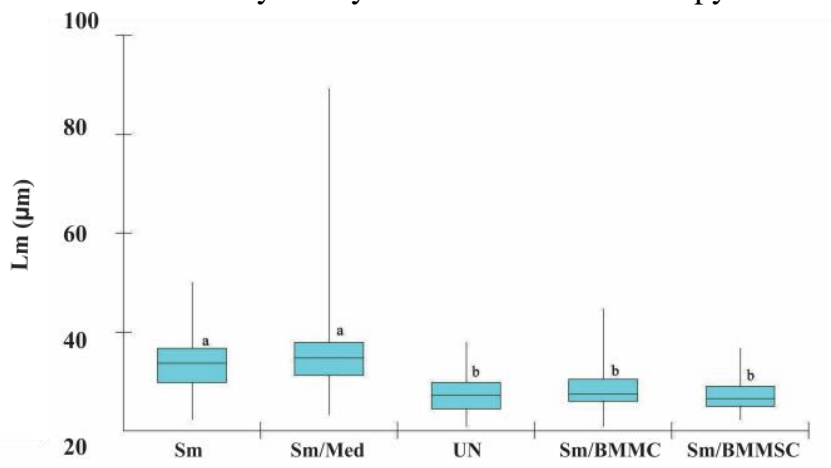

Fig. 3. Analysis of the mean linear intercept (Lm) in histological images of lung tissue from female mice (C57BL/6 background) subjected to one of the following treatments: UN, untreated; Sm, cigarette smoke exposure; $\mathrm{Sm} / \mathrm{Med}$, cigarette smoke exposure and culture medium infusion; Sm/BMMC, cigarette smoke exposure and bone marrow mononuclear cells (BMMC) transplantation; $\mathrm{Sm} / \mathrm{BMMSC}$, cigarette smoke exposure and bone marrow mesenchymal stromal cells (BMMSCs) transplantation. Data represent median and standard deviation from 90-110 Lm measurements, from 10 independent lung sections/mice, per treatment group. Data were analyzed by Kruskal-Wallis and post hoc Dunn's tests. $\mathrm{H}=184.8250$. Different letters (a and b) indicate statistically significant differences ( $p<0.0001)$. detection of green EGFP-positive cells (arrows), and DNA (labeled with DAPI, in blue). 200x magnification.

(Lm), a measure that reflects the diameter of pulmonary air spaces, as described by Weibel (1963). The induction of pulmonary emphysema was confirmed morphometrically by a significant increase in $\mathrm{Lm}$ values in the Sm group - mice with emphysema but not receiving the infusion of cells or culture medium - ( $\mathrm{p}<0.05)$, compared with the untreated (UN) group (Fig. 3). In animals with emphysema and injected with culture medium ( $\mathrm{Sm} / \mathrm{Med}$ group), $\mathrm{Lm}$ values were similar to those observed in the Sm group (Fig. 3 and 4), indicating that the administration of culture medium as a placebo did not interfere with alveolar diameter in mice with lung emphysema.

In contrast, a significant reduction in $\mathrm{Lm}$ values was observed in animals with emphysema treated with BMMC or BMMSC, when compared with Lm values in the Sm and $\mathrm{Sm} / \mathrm{Med}$ groups (Fig. 3 and 4 ). In addition, there was no statistically significant difference between $\mathrm{Lm}$ values from mice treated with cells (Sm/BMMC or Sm/BMMSC groups) and those from untreated mice without emphysema (UN group). These results show that treatment with BMMC or BMMSC promoted an effective morphological recovery of lung parenchyma. However, the lung function (i.e., ventilatory mechanics) analysis performed 21 days after cell transplantation showed no significant difference in the respiratory parameters between different groups (control and treated), as shown in Fig. 5.
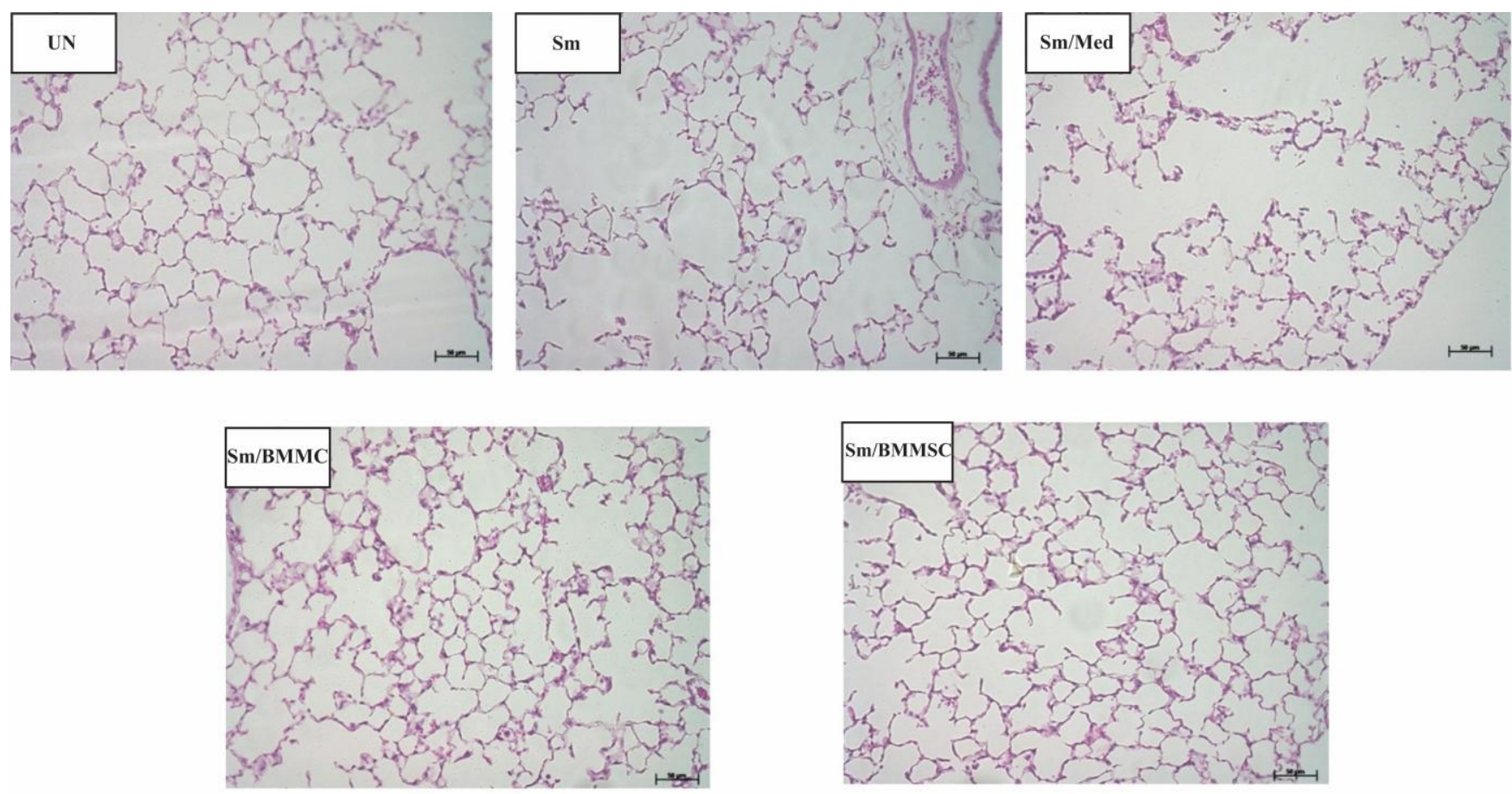

Fig.4. Histological images of lung tissue from female C57BL/6 mice subjected to one of the following treatments: UN, untreated; Sm, cigarette smoke exposure; Sm/Med, cigarette smoke exposure and culture medium infusion; Sm/BMMC, 
cigarette smoke exposure and bone marrow mononuclear cells (BMMC) transplantation; Sm/BMMSC, cigarette smoke exposure and bone marrow mesenchymal stromal cells (BMMSC) transplantation. Scale bar: $50 \mu \mathrm{m}$.
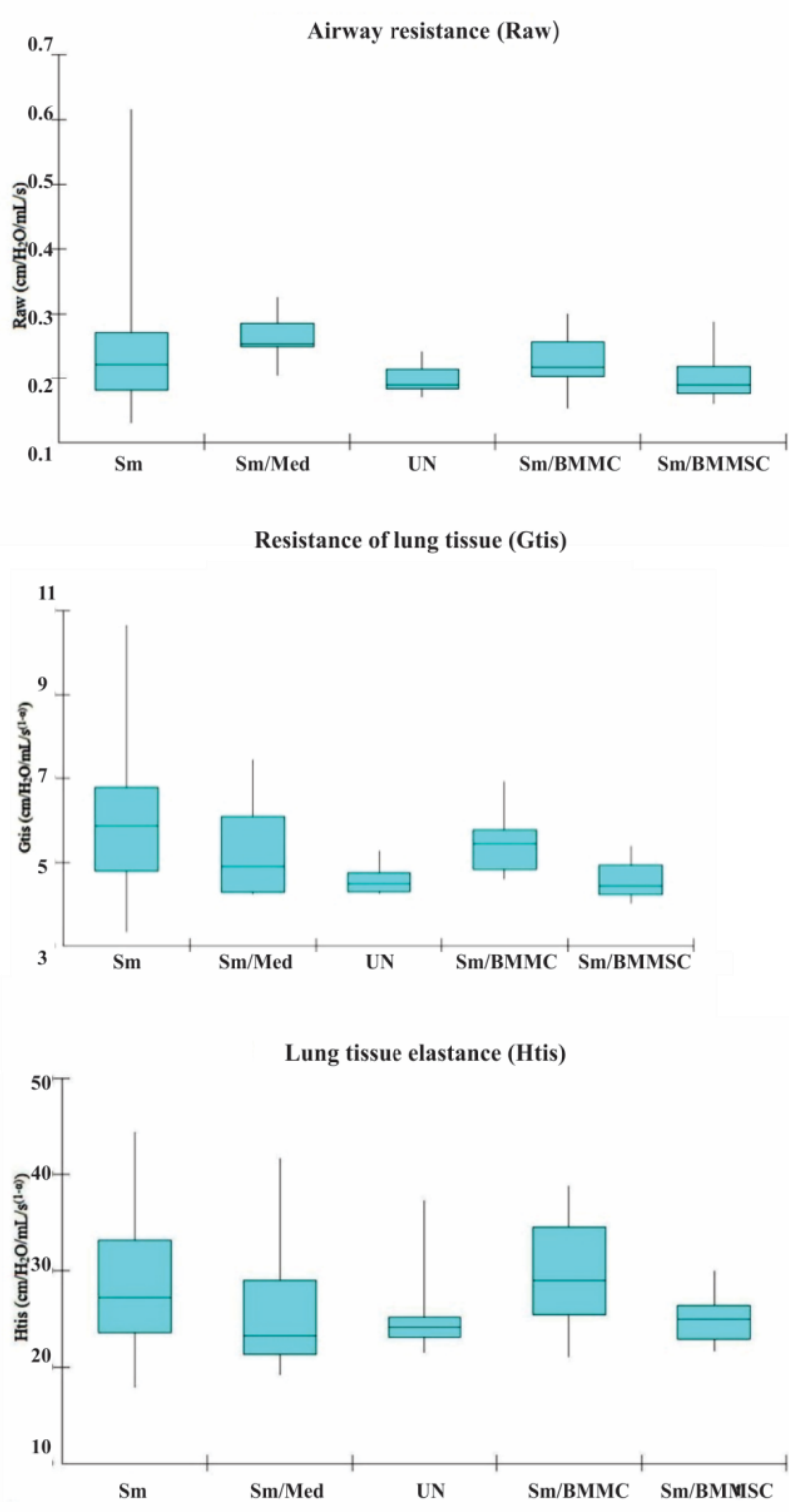

Fig. 5. Lung function analysis of female mice (C57BL/6J background) subjected to one of the following treatments: $\mathrm{UN}$, untreated; Sm, cigarette smoke exposure; Sm/Med, cigarette smoke exposure and culture medium infusion; $\mathrm{Sm} / \mathrm{BMMC}$, cigarette smoke exposure and bone marrow mononuclear cells (BMMC) transplantation; Sm/BMMSC, cigarette smoke exposure and bone marrow mesenchymal stromal cells (BMMSC) transplantation. To measure lung function parameters, mice were anesthetized (with $250 \mathrm{mg} / \mathrm{kg}$ Thiopentax) 21 days after cell transplantation, tracheotomized and connected to a ventilator for small animals. The following parameters were measured: airway resistance (Raw, in $\mathrm{A})$, lung tissue resistance (Gtis, in $\mathrm{B}$ ), and lung tissue elastance (Htis, in C). Data represent median and standard deviation values ( $\mathrm{n}=9-12$ animals/group). [Statistical analysis].
To investigate if cell transplantation improved the inflammatory process inherent to pulmonary emphysema, the patterns of metalloproteinase-9 (MMP-9) expression were compared in the different groups using immunohistochemistry. In animals exposed to cigarette smoke only (Sm group) there was a clear labeling for MMP-9 in the airway lumen and extracellular matrix, while only residual labeling was observed in the airway lumen of untreated animals (UN group), as can be seen in Fig. 6. These data confirm that exposure of mice to cigarette smoke according to the model and the apparatus used in this work promoted lung inflammation, a hallmark of pulmonary emphysema. Importantly, labeling for MMP-9 in the airway lumen of animals from the Sm/BMMSC and Sm/BMMC groups was minimal, similarly to that observed in the lungs of UN group animals (Fig. 6). Thus, treatment with BMMC or BMMSC decreases the inflammatory process characteristic of pulmonary emphysema.

\section{DISCUSSION}

The therapeutic options for pulmonary emphysema currently represent only palliative options aimed at reducing the symptoms and improving the quality of life of patients, since no available therapy results in an effective reduction of the disease burden. Given the promising effectiveness of cell therapy against different pathologies, we evaluated the potential of cell therapy in the treatment of emphysema in a mouse model of cigarette smoke-induced disease. The results presented in this study indicate that the transplantation of either BMMC or BMMSC reduced the alterations in lung parenchyma and the inflammation associated with pulmonary emphysema in mice.

The measure of the mean linear intercept (Lm), as proposed in the classic work published by Weibel, in 1963 , remains the best quantitative method to evaluate the destruction of lung parenchyma [19]. Our results showed a significant increase in alveolar diameter (as estimated by Lm values) in animals exposed to cigarette smoke but not treated with stem cells (Sm and Sm/Med groups), compared with untreated animals not exposed to cigarette smoke (UN) (Fig. 3). These results confirm that the animal model of emphysema - using an inhalation chamber developed by our group [15] - was effective in the induction of pulmonary emphysema in mice. Importantly, 21 days after cell infusion, there was no statistically significant difference between Lm values of mice treated with cells (BMMC or BMMSC) compared with those observed in the untreated group (UN) without emphysema, as presented in Fig. 5. These results indicate that cell therapy with these two cell pools tested led to reversal of the morphological emphysema-associated changes in the architecture of the lung parenchyma.

Periods of exposure to cigarette smoke vary widely between emphysema models (from 3 to 9 months) [4], [20]- 
[23]. In the present investigation, an efficient induction of emphysema in mice was observed after 3 months (90 days) of exposure to cigarette smoke. In agreement with these data, Valença and colleagues (2008) reported an increase in alveolar diameter in animals exposed to cigarette smoke for
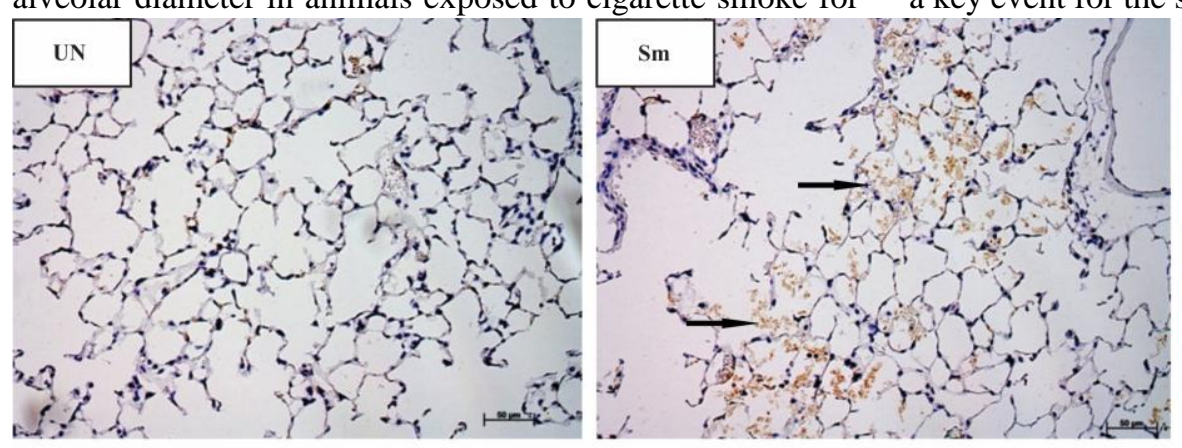

as little as 10 days [24], and Rinaldi et al. (2011) showed pulmonary emphysema induction in animals of the C57BL/6 lineage exposed to cigarette smoke for 3 months [23].

The migration of transplanted cells into the target organ is a key event for the success of cell therapy. In our study, the

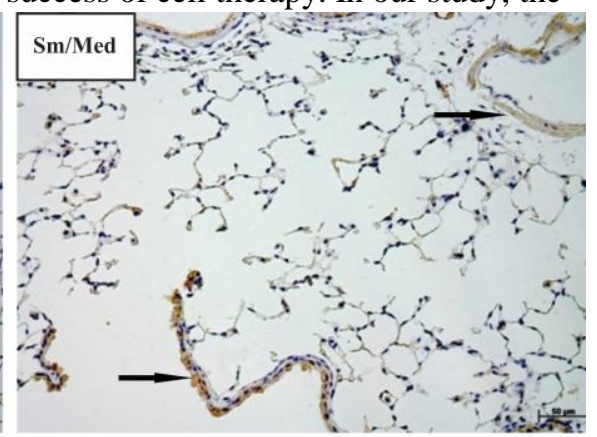

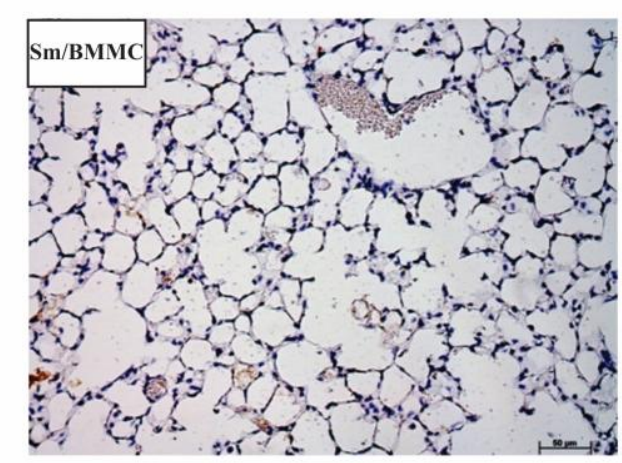

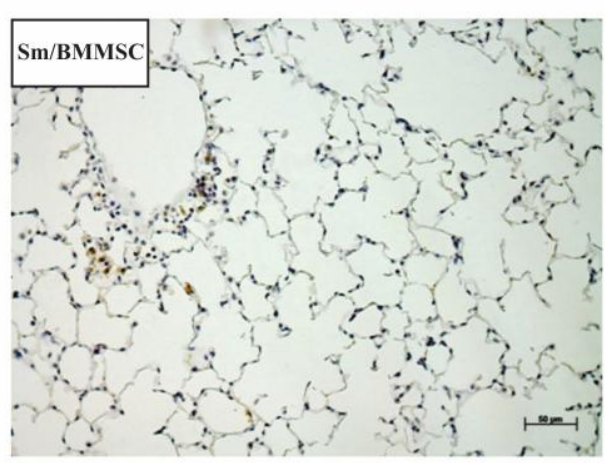

Fig. 6. Immunohistochemical detection of matrix metalloproteinase 9 (MMP-9) in lung tissue from animals in the following treatment groups: UN, untreated; $\mathrm{Sm}$, animals exposed to cigarette smoke, but not infused with cells or medium; Sm/Med, animals exposed to cigarette smoke, and infused with culture medium; $\mathrm{Sm} / \mathrm{BMMC}$, animals exposed to cigarette smoke, and infused with bone marrow mononuclear cells (BMMC); and Sm/BMMSC, animals exposed to cigarette smoke, and infused with bone marrow mesenchymal stromal cells (BMMSC). The brown precipitate (arrows) indicates the presence of MMP-9. Scale bar: 50 $\mu \mathrm{m}$.

detection of transplanted EGFP-positive cells (Fig. 2) in the lungs of treated animals provided clear evidence for efficient cell migration to the target organ.

Increased MMP-9 expression is typical of inflammatory processes in the lungs [25], and we observed evident MMP-9 staining in the groups exposed to cigarette smoke and not subjected to cell therapy ( $\mathrm{Sm}$ and $\mathrm{Sm} / \mathrm{Med}$ ). In contrast, MMP-9 staining in the extracellular matrix and airway lumen of animals subjected to cell therapy appeared reduced to levels similar to those observed in untreated (UN group) animals (Fig. 6). These results indicate that cell therapy with BMMC or BMMSC decreases the inflammation process associated with COPD.

The anti-inflammatory and immunomodulatory effects of BMMSC therapy were described previously in pulmonary disease models [26], [27]. Our results show a similar anti-inflammatory effect to that of BMMSC infusion result from infusion of a pool of BMMC in animals exposed to cigarette smoke (Fig. 6). In agreement with these results, Abreu and co-workers (2013) reported that, in a murine model of asthma, therapy with both BMMC and BMMSC reduced airway inflammation and led to remodeling of the lung tissue via modulation of IL-4, IL-13, VEGF, and TGF- $\beta$ levels. However, these effects were increased in animals subjected to BMMC therapy compared with those treated with BMMSC only, probably due to interactions between the different cell types present in the BMMC fraction [28].
Although the data on lung architecture and inflammation indicate that cell therapy reverses the destruction of lung parenchyma in emphysema (Fig. 4) the lung function analysis showed no statistically significant improvement in the elastance and airway resistance after cell therapy, in mice with smoke-induced emphysema (Fig. 5). These results may be due to technical challenges associated with producing accurate measurements of respiratory parameters in animals as small as mice. Furthermore, the induction of emphysema in cigarette smoke-exposed mice is a strain-dependent process [29]. In this way, it is also possible that the time of cigarette smoke-exposure used in this study (3 months) was not sufficient to produce meaningful functional changes in the respiratory parameters in all animals. This hypothesis is supported by several other studies. Foronjy and co-workers (2005) exposed two lineages of C57 mice to cigarette smoke for longer periods of time and also failed to observe functional changes in the respiratory parameters in cigarette smoke-exposed mice, despite significant increases in $\mathrm{Lm}$ values relative to control (not exposed) groups [30]. Subsequently, Wright et al. (2008) showed that mice with moderate emphysema had normal respiratory function values, while these values were significantly altered in animals with advanced disease [31]. Therefore, it is possible that the animals in our study did not achieve a severe emphysema stage, which may underlie the lack of statistically significant alterations in lung function parameters after cigarette smoke 
exposure.

As a whole, our data show that cell therapy with BMMC or BMMSC in animals with cigarette smoke-induced emphysema improves the morphological alterations in lung parenchyma and reduces the lung inflammation associated with COPD. These results are in agreement with previous findings of our group and the results published by other research groups that show morphological improvement of the lung parenchyma after cell therapy with BMMC or BMMSC [5]. [10], [12], [32]- [34]. Thus, we propose that cell therapy with either BMMC or BMMSC is a potential therapeutic alternative for lung morphological repair after injury.

Finally, it should be emphasized that the results in animal models are important for the advancement in knowledge of the mechanisms orchestrating lung regeneration processes after injury [9], [20], [35], [36]. These results added to the set of information obtained in pioneering clinical trials in human patients open new perspectives for the implementation of large multicenter clinical trials to allow the verification with greater consistency the efficacy of cell-based therapies in obstructive pulmonary diseases [4], [5], [32], [34], [37]- [40].

\section{ACKNOWLEDGMENT}

The authors thank Fundação para o Desenvolvimento da UNESP (Fundunesp), Assis City Hall (SP, Brazil) and CIVAP/Saúde (SP, Brazil) for financial support. The authors gratefully thank Dr. Fernanda Degobbi Tenorio Quirino dos Santos Lopes and staff of the Experimental Therapeutic Laboratory I/LIM/FMUSP at the University of São Paulo for their assistance with lung function tests.

\section{REFERENCES}

[1] Global Initiative for Chronic Obstructive Lung Disease: Pocket guide to COPD diagnosis, management and prevention. Updated 2015 GOLD, 2015: 1-32. Available: http://www.goldcopd.org/.

[2] World Health Organization. WHO. Global Alliance against Chronic Respiratory Diseases (GARD) - 8th General Meeting Report, Astana, Kazakhstan, 2013.

[3] J.T. Ribeiro-Paes JT, A. Bilaqui, O.T. Greco, M.A. Ruiz, M.Y. Marcelino, T. Stessuk, et al. "Unicentric study of cell therapy in chronic obstructive pulmonary disease/pulmonary emphysema", Int $J$ Chron Obstruct Pulmon Dis., vol. 6, 2011; pp. 63-71.

[4] C.A. Faria, R.H. Kozma, T. Stessuk, J.T. Ribeiro-Paes. "Experimental basis and new insights for cell therapy in chronic obstructive pulmonary disease", Stem Cell Rev., vol. 8(4), 2012, pp. 1236-1244.

[5] J.T. Ribeiro-Paes, T. Stessuk, R.H. Kozma. "Cell therapy in chronic obstructive pulmonary disease: state of the art and perspectives" In Chronic Obstructive Pulmonary Disease: Current Concepts and Practice, O Kian-Chung, Ed. Croatia: InTech; 2012. pp. 455-474.

[6] V. Sueblinvong, D.J. Weiss. "Cell therapy approaches for lung diseases: current status", Curr Opin Pharmacol., vol. 9(3), 2009, pp. 268-273.

[7] B.T. Suratt, C.D. Cool, A.E. Serls, L. Chen, M. Varella-Garcia, E.J Shpall, et al. "Human pulmonary chimerism after hematopoietic stem cell transplantation”, Am J Respir Crit Car Med., vol. 168(3), 2003, pp. 318-322.

[8] S. Schrepfer, T. Deuse, H. Reichenspurner, M.P. Fischbein, R.C. Robbins, M.P. Pelletier. "Stem Cell Transplantation: The Lung Barrier", Transplant Proc., vol. 39(2), 2007, pp. 573-576.

[9] A.M. Katsha, S. Ohkouchi, H. Xin, M. Kanehira, R. Sun, T. Nukiwa, et al. "Paracrine factors of multipotent stromal cells ameliorate lung injury in an elastase-induced emphysema model", Mol Ther., vol 19(1), 2011, pp. 196-203.

[10] N. Longhini-Dos-Santos, V.A. Barbosa-de-Oliveira, R.H. Kozma, C.A Faria, T. Stessuk, F. Frei, et al. "Cell therapy with bone marrow mononuclear cells in elastase-induced pulmonary emphysema", Stem Cell Rev., vol. 9(2), 2013, pp. 210-218.
[11] S. Cendon, C. Battlehner, G. Lorenzi-Filho, M. Dohlnikoff, P. Pereira, G. Conceição, et al. "Pulmonary emphysema induced by passive smoking: an experimental study in rats", Braz J Med Biol Res., vol. 30(10), 1997, pp. 1241-1247.

[12] H. Zheng, Y. Liu, T. Huang, Z. Fang, G. Li, S. He. "Development and characterization of a rat model of chronic obstructive pulmonary disease (COPD) induced by side stream cigarette smoke", Toxicol Lett., vol 189(3), 2009, pp. 225-234.

[13] J.R. Jardim, L. Bizeto, A. Fleig Mayer, A. Camelier, F.W. Rosa, D. Oliveira, et al. "An inhalation chamber model for controlled studies of tobacco smoke toxicity in rodents", Arch Bronconeumol., vol 46(9), 2010, pp. 455-458

[14] J.W. Huh, S.Y. Kim, J.H. Lee, J.S. Lee, Q.V. Ta, M.J. Kim, et al. "Bone marrow cells repair cigarette smoke-induced emphysema in rats", Am J Physiol. Lung Cell Mol Physiol., vol 301(3), 2011, pp. 255-266.

[15] R.H. Kozma, E.M. Alves, V.A. Barbosa-de-Oliveira, F.D.T.Q.S. Lopes, R.C. Guardia, H.V. Buzo, et al. "A new experimental model of cigarette smoke-induced emphysema in Wistar rats", J Bras Pneumol., vol. 40(1), 2014, pp. 46-54

[16] A. Giangreco, E.N. Arwert, I.R. Rosewell, J. Snyder, F.M. Watt, B.R Stripp. "Stem cells are dispensable for lung homeostasis but restore airways after injury", Proc Natl AcadSci U S A, vol. 106(23), 2009, pp. 9286-9291.

[17] K.H. Yoo, I.K. Jang, M.W. Lee, H.E. Kim, M.S. Yang, Y. Eom, et al. "Comparison of immunomodulatory properties of mesenchymal stem cells derived from adult human tissues", Cell Immunol., vol. 259(2), 2009, pp. 150-156.

[18] E. Weibel. "Principles and methods for the morphometric study of the lung and other organs", Lab Invest., vol. 12, 1963, pp. 131-155.

[19] W.M. Thurlbeck. "Internal surface area and other measurements in emphysema", Thorax, vol. 22(6), 1967, pp. 483-496.

[20] J.P.S. Peron, A.A. Brito, M. Pelatti, W.N. Brandão, L.B. Vitoretti, F.R Greiffo, et al. "Human tubal-derived mesenchymal stromal cells associated with low level laser therapy significantly reduces cigarette smoke-induced COPD in C57BL/6 mice", PLoS One, vol 10(8), 2015, e0139294.

[21] T. Maeno, A.M. Houghton, P.A. Quintero, S. Grumelli, C.A. Owen, S.D. Shapiro. "CD8+ T cells are required for inflammation and destruction in cigarette smoke-induced emphysema in mice", $J$ Immunol., vol 178(12), 2007, pp. 8090-8096.

[22] H.R. Gosker, R.C. Langen, K.R. Bracke, G.F. Joos, G.G. Brusselle, C. Steele, et al. "Extra pulmonary manifestations of chronic obstructive pulmonary disease in a mouse model of chronic cigarette smoke exposure", Am J Respir Cell Mol Biol., vol. 40(6), 2009, pp. 710-716.

[23] M. Rinaldi, K. Maes, S. De Vleeschauwer, D. Thomas, E.K. Verbeken, M. Decramer, et al. "Long-term nose-only cigarette smoke exposure induces emphysema and mild skeletal muscle dysfunction in mice", Dis Model Mech., vol. 5(3), 2012, pp. 333-341.

[24] S.S. Valença, L.C. Porto. "Estudo imunohistoquímico do remodelamento pulmonar em camundongos expostos à fumaça de cigarro", J Bras Pneumol., vol. 34(10), 2008, pp. 787-795.

[25] F. Sampsonas, A. Kaparianos, D. Lykouras, K. Karkoulias, K Spiropoulos. "DNA sequence variations of metalloproteinases: their role in asthma and COPD", Postgrad Med J., vol. 83(978), 2007, pp. $244-250$

[26] L.A. Ortiz, F. Gambelli, C. McBride, D. Gaupp, M. Baddoo, N. Kaminski, et al. "Mesenchymal stem cell engraftment in lung is enhanced in response to bleomycin exposure and ameliorates its fibrotic effects", Proc Natl Acad Sci U S A, vol. 100(14), 2003, pp. 8407-8411.

[27] M. Rojas, J. Xu, C.R. Woods, A.L. Mora, L. Spears, J. Roman, et al. "Bone Marrow-Derived mesenchymal stem cells in repair of the injured lung", Am J Respir Cell Mol Biol., vol. 33(2), 2005, pp. $145-152$

[28] S.C. Abreu, M.A. Antunes, J.C. Castro, M.V. Oliveira, E. Bandeira, D.S. Ornellas, et al. "Bone marrow-derived mononuclear cells vs. Mesenchymal stromal cells in experimental allergic asthma", Respir Phisiol Neurobiol., vol. 187(2), 2013, pp. 190-198.

[29] M.E. Laucho-Contreras, K.L. Taylor, R. Mahadeva, S.S. Boukedes, C.A. Owen. "Automated measurement of pulmonary emphysema and small airway remodeling in cigarette smoke-exposed mice", $J$ Vis Exp., vol. $95,2015,52236$

[30] R.F. Foronjy, B.A. Mercer, M.W. Maxfield, C.A. Powell, J D'Armiento. "Structural emphysema does not correlate with lung compliance: lessons from the mouse smoking model", Exp Lung Res., vol. 31(6), 2005, pp. 547-562.

[31] J.L. Wright, M. Cosio, A. Churg. "Animal models of chronic obstructive pulmonary disease", Am J Physiol. Lung Cell Mol Physiol. vol. 295(1), 2008, L1-L15. 
[32] A. Tzouvelekis, V. Paspaliaris, G. Koliakos, P. Ntolios, E. Bouros, A. Oikonomou, et al. "A prospective, non-randomized, no placebo-controlled, phase Ib clinical trial to study the safety of the adipose derived stromal cells-stromal vascular fraction in idiopathic pulmonary fibrosis", J Transl Med., vol. 11, 2013, 171.

[33] D.J. Weiss, R. Casaburi, R. Flannery, M. Leroux-Williams, D.P. Tashkin. "A placebo-controlled randomized trial of mesenchymal stem cells in Chronic Obstructive Pulmonary Disease", Chest, vol. 143(6), 2013, pp. 1590-1598.

[34] M. Conese, D. Piro, A. Carbone, S. Castellani, S. Di Gioia. "Hematopoietic and mesenchymal stem cells for the treatment of chronic respiratory diseases: role of plasticity and heterogeneity", Scientific World Journal, vol. 2014, 2014, 859817.

[35] M.Y. Marcelino, N.L. Fuoco, C.A. Faria, R.L. Kozma, L.F. Marques, J.T. Ribeiro-Paes. "Animal models in chronic obstructive pulmonary disease - an overview”, Exp Lung Res., vol. 40(6), 2014, pp. 259-271.

[36] F. Polverino, M. Doyle-Eisele, J. McDonald, J.A. Wilder, C. Royer, M. Laucho-Contreras, et al. "A novel nonhuman primate model of cigarette smoke-induced airway disease", Am J Pathol., vol. 185(3), 2015, pp. 741-755.

[37] G. Caramori, P. Casolari, E. Garofano, F. Mazzoni, I. Marchi, M. Contoli, et al. "Role of stem cells in the phatogenesis of chronic obstructive pulmonary disease and of pulmonary emphysema", Recenti Prog Med., vol. 103(1), 2012, pp. 31-40.

[38] C. Agostini. "Stem cell therapy for chronic lung diseases: hope and reality", Respir Med., vol. 104, 2010, S86-91.

[39] R. Lipsi, P. Rogliani, L. Calzetta, A. Segreti, M. Cazzola. "The clinical use of regenerative therapy in COPD", Int J Chron Obstruct Pulmon Dis., vol. 9, 2014, pp. 1389-1396.

[40] X. Liu, Q. Fang, H. Kim. "Preclinical studies of mesenchymal stem cells (MSC) administration in chronic obstructive pulmonary disease (COPD): A systematic review and meta-analysis", PLoS One, vol. 11(6), 2016, e0157099.

Nathalia Longhini-dos-Santos (MSc, University of São Paulo, Brazil). Her work is directed towards cell therapy and stem cells biology, focused mainly on pulmonary emphysema. She is the first author of the article "Cell Therapy with bone marrow mononuclear cells in elastase-induced pulmonary emphysema (2012)",

Valter Abraão Barbosa-de-Oliveira (MSc, University of São Paulo, Brazil). He has investigated experimental treatments with bone marrow stem cells for pulmonary emphysema in animal models. He developed a standardized methodology for animal models of pulmonary emphysema using direct exposure to cigarette smoke. He is author of the original articles "Cell Therapy with bone marrow mononuclear cells in elastase-induced pulmonary emphysema (2012)" and "Estudo comparativo de dois procedimentos de fixação histológica para análise do enfisema pulmonary induzido experimentalmente (2011)".

Talita Stessuk (PhD, University of São Paulo, Brazil). Dr. Stessuk is currently a postdoc fellow at Radboud University Medical Center (Nijmegen, The Netherlands) focused on bone tissue engineering. During her PhD studies, she conducted a clinical study to investigate the effects of mesenchymal stromal cells and platelet-rich plasma on wound healing of diabetic patients. Solid background on cell therapy with bone marrow mononuclear cells in animal models of pulmonary emphysema and patients with COPD.

Marna Eliana Sakalem (MSc, PhD, São Paulo State University, Brazil). Main topics of research include behavior and cognition, adult neurogenesis and stem cells. Stronger background on pharmacology and compared anatomy and physiology.

João Tadeu Ribeiro-Paes (MD, PhD. São Paulo State University, Brazil). Prof. Ribeiro-Paes is currently an associate professor and researcher at São Paulo State University - UNESP - Brazil. He has expertise in Genetics with emphasis in Human and Medical Genetics, working mainly on the following topics: stem cells, cell therapy in experimental models and in the treatment of human patients with Chronic Obstructive Pulmonary Disease (COPD). He also has projects focused on the physical chemistry analysis of the interaction between biomaterials and mesenchymal stromal cells and the use of biomaterials and human adipose-derived mesenchymal stromal cells for the treatment of chronic wounds. 